\title{
Reference spirometric values in a Sudanese cohort
}

\author{
A.A. Bashir ${ }^{1}$ and O.A.A. Musa ${ }^{2}$
}

$$
\begin{aligned}
& \text { قِيَم مرجعية للقياسات التنفسية في أترابيَّة سودانيَّة }
\end{aligned}
$$

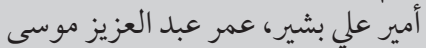

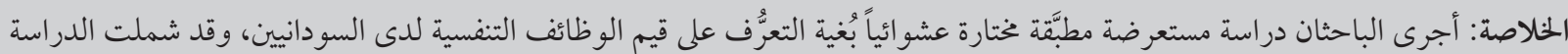

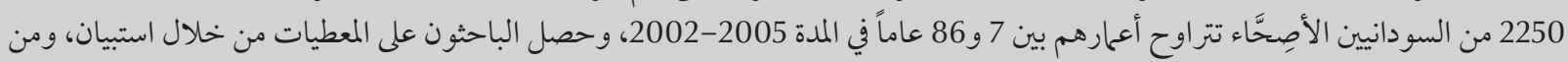

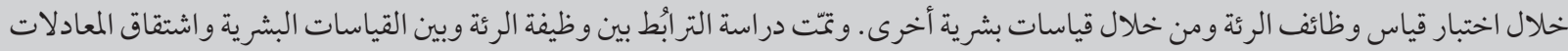

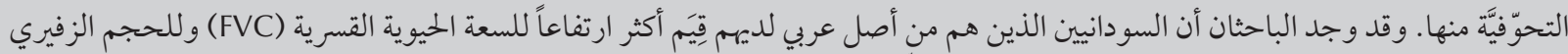

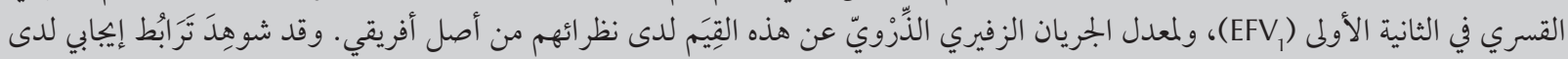

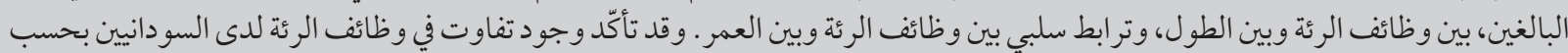

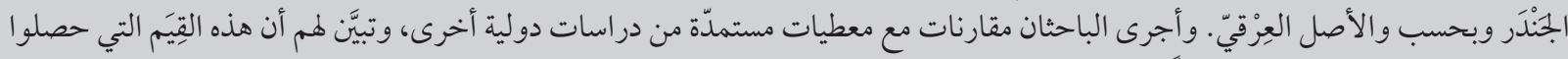

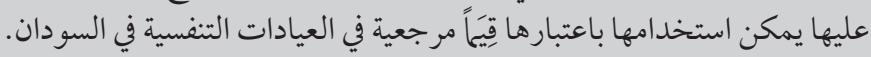

ABSTRACT To determine normal values of respiratory function for Sudanese, a randomized stratified crosssectional study was performed on 2250 healthy Sudanese aged 7-86 years in 2002-05. Data were obtained through a questionnaire, pulmonary function testing and taking anthropometric measurements. Lung function and anthropometric measurements were correlated and regression equations were derived. Sudanese of Arab ethnic background had significantly higher forced vital capacity (FVC), forced expiratory volume in 1 (first) second (FEV1) and peak expiratory flow rate (PEFR) than those of African ethnicity. In adults a positive correlation was found between lung function and height and a negative correlation with age. Gender and ethnic variations in Sudanese lung function were confirmed. Comparisons were made with data from other international studies. These values can be used as reference values in respiratory clinics in Sudan.

\section{Valeurs spirométriques de référence dans une cohorte soudanaise}

RÉSUMÉ Afin de déterminer les valeurs normales de la fonction respiratoire des Soudanais, une étude transversale, randomisée et stratifiée a été réalisée entre 2002 et 2005, auprès de 2250 personnes en bonne santé âgées de 7 à 86 ans. Les données ont été obtenues au moyen d'un questionnaire, d'une exploration fonctionnelle respiratoire et d'une prise de mesures anthropométriques. La fonction pulmonaire et les mesures anthropométriques étaient corrélées. Des équations de régression ont été établies. Les Soudanais d'origine arabe avaient une capacité vitale, un volume expiratoire maximal seconde et un débit expiratoire de pointe nettement supérieurs à ceux des Soudanais d'origine africaine. Chez les adultes, une corrélation positive a été observée entre la fonction pulmonaire et la taille, alors qu'une corrélation négative a été notée avec l'âge. Les variations dans les fonctions pulmonaires des Soudanais en fonction du sexe et de l'origine ethnique ont été confirmées. Des comparaisons ont été faites avec les données d'autres études internationales. Ces valeurs peuvent être utilisées en tant que valeurs de référence dans les centres soudanais spécialisés en santé respiratoire. 


\section{Introduction}

Reference values for health measures can be subject-based using baseline values from the same individual obtained when he/she in a defined state of health or population-based using data obtained from a group of welldefined reference individuals. In the case of respiratory parameters, prediction equations obtained from a reference population provide a baseline for evaluating the pulmonary function of a subject, based usually on the person's standing height, age and sex [1].

There are well-documented ethnic, sex, age, geographical, postural, socioenvironmental, occupational and instrumental variations in lung function measures. Significantly higher vital capacities were found in a white population compared with blacks $[2,3]$ and in Africans compared with Indians [4].American Indians showed lower forced vital capacity (FVC) and forced expiratory volume in 1 second (FEV1) values than American whites [5]. Lower lung volumes and capacities [6] as well as flow rates [7] have been recorded from females compared with males. An inverse relationship between age and lung function values is present in adults and a direct relationship is found with height and weight [8].

A reference set of normallung function values are needed in Sudan for use in diagnosis, follow-up, pre-surgical assessment and research. The earliest attempt to obtain normal spirometric values, in 1977, used a small sample and included only 2 areas of Sudan [9]. The study found that the Sudanese values were lower than the international ones, with differences between inhabitants of different areas [10]. A pilot study in Gezira (central Sudan) in 1998 gave similar indicators and confirmed the feasibility of performing a large national study to derive the normal spirometric values for Sudanese [11].
The present study was designed to find out the normal values of FVC, FEV1, FEV1/FVC\% and peak expiratory flow rate (PEFR) for normal Sudanese, and to correlate the obtained lung function values with age, body weight, height, sex and ethnic group so as to derive prediction equations for normal lung function measures for adults and children of both sexes. Spirometric values obtained from the current study will provide the only large-scale data for eastern and central Africa.

\section{Methods}

\section{Study design}

This was a cross-sectional study performed over the period 2002-05 on subjects from different regions of Sudan. Ethical clearance for the study was issued by the administration of the Faculty of Medicine, University of Gezira.

Regional because in Sudan each region constitutes a specific ethnic group, the only exception is the southerners that we take them from northern regions.

\section{Subjects}

A total of 2250 Sudanese subjects aged 7-86 years old ( 1162 males and 1088 females) were included. The sample size was calculated using a confidence level of $95 \%$, confidence interval of 2.07 and estimated population of 30-40 million. Sampling was of stratified type whereby the population was divided into subgroups by age, sex and geographical region then random selection was performed within the subgroups from the available lists [12]. Subjects were chosen randomly from volunteers from a number of occupational groups (manual workers, professionals, students, pensioners, housewives), recruited from various locations such as government ministries, administration departments, universities, schools, sport clubs, mosques and churches.

Subjects were chosen from different regions to reflect different regional tribal groups: central (Khartoum, Medani and Kosti), north (Atbra), west (Elfashir, Nyala, Jabal Mara) and east (Gadarif).Data for the south were taken from south Sudanese people living in Rabak (near the border with South Sudan) and in Khartoum. The ethnic background was established on a regional basis as specific tribes are resident in each region. Subjects were classified as Arab (north, west and east Sudanese) and African (south Sudanese) ethnic origin. Ethnic group was established from a questionnaire about the parents' and grandparents' tribes.

Subjects were considered "normal" if they had never smoked tobacco; reported no history of symptoms of respiratory diseases; had normal cardiopulmonary signs on clinical examination; had no history of occupation exposure to dust; and were willing and able to cooperate [7]. Subjects were excluded if they did not satisfy the inclusion criteria; if they were smokers; if they had respiratory or cardiovascular disease; or if they did not perform the respiratory tests correctly. The response rate of our subjects to the tests was over $95 \%$.

\section{Data collection}

A questionnaire was designed as a modification of the British Medical Research Council and Los Angeles internet protocol television questionnaires. The questionnaire included: personal data; habits (smoking, sports); family history of respiratory illness (bronchial asthma and allergies); and personal health condition.

Medical examination and pulmonary function tests were performed. A stadiometer was used to measure the standing height of the subject in centimetres. A sensitive balance was used to measure the body weight of the 
subject in kilograms. Skinfold callipers was used to measure the thickness of the skin with its underlying layer of fat at the back of the arm. It has a spring that exerts pressure on the skinfold, generally $10 \mathrm{~g} / \mathrm{m}^{2}$ and a scale which measures the thickness in millimetres [13].

A pocket spirometer (MicroPlus, Micro Medical) was used to measure FVC, FEV1, FEV1/FVC\% and PEFR. It meets the recommendations of both the European Respiratory Society and British Thoracic Society [14]. The spirometer was periodically standardized after about 100 tests through re-testing of a sample of the same subjects and comparing with the previous readings and also by comparing readings with those of a standard instrument (Micro Medical). Use of the spirometer was demonstrated to each subject. After maximal inspiration, the subject blew forcibly and continuously into the mouthpiece of the spirometer and the highest measurement of 3 trials was taken as the most representative of the subject's ability. FVC, FEV1, FEV1/FVC\% and PERF were recorded. Subjects were excluded if they failed to inspire before breathing out, failed to exhale due to inability to relax or leaked the air by expiring before holding the mouthpiece or not holding their lips tightly around the mouthpiece. The estimated altitude of the region at which the study was done and the room temperature were taken.

\section{Data analysis}

Partial correlation test was used. Student $t$-test and analysis of variance were used to test the significance of differences $(P$ $<0.05$ ). Multiple regression analysis was used to derive regression equations using SPSS, version 11 computer programme.

\section{Results}

Table 1 shows the distribution of the study sample by sex and region of Sudan.

\begin{tabular}{lccc}
\hline \multicolumn{3}{l}{ Table 1 Distribution of the study subjects by sex and region of Sudan } & \\
\hline Region & Males & Females & Total \\
& No. & No. & No. \\
West Sudan & 394 & 299 & 693 \\
East Sudan & 291 & 244 & 535 \\
Central Sudan & 219 & 258 & 477 \\
North Sudan & 103 & 140 & 243 \\
South Sudan & 155 & 147 & 302 \\
Total & 1162 & 1088 & 2250 \\
\hline
\end{tabular}

Descriptive and lung function parameters were derived for males and females in different age groups (Tables 2 and 3 ).

Table 4 shows lung function values in Sudanese males by height and weight. There was an observable positive correlation between measures oflung volume and both weight and standing height, except at the greatest height 181-190 $\mathrm{cm}$ and body weights $(91-100 \mathrm{~kg})$, where there was a drop in values.

There was significant negative correlation in adults between age and ventilatory function $(r=0.49)$. The highest values of FVC and FEV1 [3.77

\begin{tabular}{|c|c|c|c|}
\hline \multicolumn{4}{|c|}{$\begin{array}{l}\text { Table } 2 \text { Descriptive data and lung function for normal male Sudanese by age } \\
\text { group }\end{array}$} \\
\hline Variable & $\begin{array}{l}\text { Adults } \geq 20 \text { years } \\
\text { Mean }(\mathrm{SD})\end{array}$ & $\begin{array}{c}\text { Adults }>15-<20 \text { years } \\
\quad \text { Mean }(\mathrm{SD})\end{array}$ & $\begin{array}{l}\text { Children } \leq 15 \text { years } \\
\text { Mean }(\mathrm{SD})\end{array}$ \\
\hline Age (years) & $38.1(13.2)$ & $16.9(0.9)$ & $12.6(1.9)$ \\
\hline Height (cm) & $172.4(7.2)$ & $165.4(10.1)$ & 146.4 (10.8) \\
\hline Weight (kg) & $65.6(12.0)$ & $52.9(13.0)$ & 35.2 (9.9) \\
\hline Lean mass (kg) & $52.5(8.4)$ & 44.7 (9.7) & $30.4(7.8)$ \\
\hline $\mathrm{FVC}(\mathrm{L})$ & $3.48(0.68)$ & $3.26(0.71)$ & $2.11(0.51)$ \\
\hline FEV1 (L) & $3.18(0.61)$ & $2.95(0.64)$ & $1.90(0.44)$ \\
\hline FEVI/FVC (\%) & $91.3(5.6)$ & $90.5(5.9)$ & $90.5(7.9)$ \\
\hline PEFR (L/min) & 486 (107) & $410(100)$ & $290(75)$ \\
\hline
\end{tabular}

$S D=$ standard deviation.

$F V C=$ forced vital capacity; $F E V 7=$ forced expiratory volume in 1 second; PEFR = peak expiratory flow rate.

\begin{tabular}{lcc}
\hline $\begin{array}{l}\text { Table } 3 \text { Descriptive data and lung function for normal female Sudanese by age } \\
\text { group }\end{array}$ & Adults > 15 years & Children $\leq \mathbf{1 5}$ years \\
Variable & Mean (SEM) & Mean (SEM) \\
& $28.4(0.4)$ & $11.5(0.1)$ \\
Age (years) & $161.3(0.3)$ & $143.0(0.6)$ \\
Height (cm) & $57.7(0.4)$ & $33.7(0.5)$ \\
Weight (kg) & $42.3(0.3)$ & $27.1(0.4)$ \\
Lean mass (kg) & $2.66(0.02)$ & $1.97(0.03)$ \\
FVC (L) & $2.42(0.02)$ & $1.76(0.02)$ \\
FEVI (L) & $91.1(0.2)$ & $89.8(0.5)$ \\
FEVI/FVC (\%) & $346(2.3)$ & $264(3.0)$ \\
PEFR (L/min) & &
\end{tabular}

SEM = standard error of the mean .

$F V C=$ forced vital capacity; $F E V I=$ forced expiratory volume in 1 second; $P E F R=$ peak expiratory flow rate. 


\begin{tabular}{|c|c|c|c|}
\hline \multirow[t]{2}{*}{ Variable } & FVC (L) & FEV1 (L) & $\operatorname{PEFR}(\mathrm{L} / \mathrm{min})$ \\
\hline & Mean (SD) & Mean (SD) & Mean (SD) \\
\hline \multicolumn{4}{|c|}{ Height (cm) } \\
\hline $121-130$ & $1.65(0.40)$ & $1.42(0.32)$ & $172(38)$ \\
\hline $131-140$ & $1.86(0.53)$ & $1.62(0.22)$ & $251(46)$ \\
\hline $141-150$ & $2.03(0.49)$ & $1.70(0.25)$ & 239 (61) \\
\hline $151-160$ & $2.80(0.70)$ & $2.29(0.55)$ & 294 (95) \\
\hline $161-170$ & $3.29(0.66)$ & $2.98(0.58)$ & 446 (110) \\
\hline $171-180$ & $3.66(0.89)$ & $3.29(0.61)$ & 479 (107) \\
\hline 181-190 & $3.76(1.29)$ & $3.19(0.91)$ & 459 (109) \\
\hline \multicolumn{4}{|c|}{ Weight (kg) } \\
\hline $21-30$ & $1.82(0.37)$ & $1.57(0.20)$ & $211(45)$ \\
\hline $31-40$ & $2.30(0.67)$ & $1.85(0.35)$ & $262(63)$ \\
\hline $41-50$ & $2.46(0.85)$ & $2.13(0.63)$ & 304 (97) \\
\hline $51-60$ & $3.40(0.60)$ & $3.09(0.57)$ & 466 (124) \\
\hline $61-70$ & $3.55(0.71)$ & $3.20(0.60)$ & $468(91)$ \\
\hline $71-80$ & $3.65(0.87)$ & $3.30(0.78)$ & $480(132)$ \\
\hline $81-90$ & $4.30(0.86)$ & $3.41(0.50)$ & 497 (88) \\
\hline 91-100 & $3.67(0.64)$ & $3.22(0.43)$ & $385(54)$ \\
\hline
\end{tabular}

$S D=$ standard deviation

$F V C=$ forced vital capacity; $F E V 7=$ forced expiratory volume in 1 second; $P E F R=$ peak expiratory flow rate
(SD 0.59) L and 3.54 (SD 0.50) L respectively] were found in the age group $21-30$ years old and the lowest values in the age group $71-80$ years $[2.45$ (SD 0.16) $\mathrm{L}$ versus 2.18 (SD 0.32) L respectively] (Table 5). The highest mean value of PEFR [502 (SD 123) $\mathrm{L} / \mathrm{min}$ ] was in the age group $31-40$ years old.

Lung function parameters also correlated with each other. There was a high correlation between FEV1 and FVC $(r=0.97)$. PEFR with FEV1 $(r=$ $0.75)$, FVC with PEFR $(r=0.70)$, FVC with FEV1/FVC $(r=0.12)$ and PEFR with FEV1/FVC $(r=0.29)$.

FVC, FEV1 and PEFR prediction equations by age and height for Sudanese adults and children of both sexes were derived using multiple regression (Table 6). In general these showed low multiple correlation coefficients $(R)$ and large standard errors of the estimate (SEE),

The mean lung function values of all Sudanese at height $170 \mathrm{~cm}$ and age 30 years for FCV, FEV1, PEFR and FEV1/ FVC were $3.59 \mathrm{~L}, 3.28 \mathrm{~L}, 499.5 \mathrm{~L} / \mathrm{min}$

\begin{tabular}{|lccc|}
\hline \multicolumn{4}{l}{ Table 5 Lung function values in adult Sudanese males by age group } \\
\hline Age (years) & FVC (L) & FEV1 (L) & PEFR (L/min) \\
& Mean (SD) & Mean (SD) & Mean (SD) \\
$21-30$ & $3.77(0.59)$ & $3.54(0.50)$ & $501(84)$ \\
$31-40$ & $3.65(0.95)$ & $3.24(0.76)$ & $502(123)$ \\
$41-50$ & $3.42(0.57)$ & $3.07(0.48)$ & $444(79)$ \\
$51-60$ & $3.41(0.73)$ & $3.05(0.55)$ & $426(87)$ \\
$61-70$ & $2.97(0.66)$ & $2.53(0.48)$ & $374(107)$ \\
$71-80$ & $2.45(0.16)$ & $2.18(0.32)$ & $312(87)$ \\
\hline
\end{tabular}

$S D=$ standard deviation

$F V C=$ forced vital capacity; $F E V 7=$ forced expiratory volume in 1 second; $P E F R=$ peak expiratory flow rate and $90.6 \%$ respectively. The regional prediction equations for adult male $\mathrm{Su}$ danese ( $\geq 20$ years) and the predicted means at height $170 \mathrm{~cm}$ and age 30 years are shown in Table 7. Predicted lung function values of the east and central Sudanese were in between the values for north and south Sudanese. The predicted means of FVC, FEV1 and PEFR in the different regions did not differ significantly from the general predicted means for all Sudanese combined.

Actual and predicted mean lung function values for Sudanese adult males of Arab and African ethic backgrounds (at height $170 \mathrm{~cm}$ and 35 age years) are shown in Table 8 and Figures 1 and 2 . The predicted mean values of the people of Arab ethnic background (north, east and west Sudanese) were significantly higher than those of African ethnic background (south Sudanese) for FVC (3.66 L versus $3.26 \mathrm{~L})$ and FEV1 (3.26 versus $2.96 \mathrm{~L}$ ) and PEFR (519 versus $419 \mathrm{~L} / \mathrm{min})(P>0.05)$.

\section{Discussion}

Previous studies in Sudan to obtain reference spirometry values were limited due to small sample sizes and uneven age distribution within samples. Among the 29 studies of healthy African adults published between 1965 and 1990 involving 9690 men and 2638 women of sub-Saharan African ancestry, only 1 study was based on a group larger than ours [15-17]. Our sample size aimed to be statistically representative of the whole Sudanese population by including all regions and different occupation sectors of the community.

The highest values of FVC and FEV1 were found in the age group 21-30 years old. Others have shown that lung function increases up to 25 years of age [18]. Meanwhile the highest mean values of PEFR were found in the age group 31-40 years old, and this 


\begin{tabular}{|c|c|c|c|c|c|}
\hline \multirow[t]{2}{*}{ Sex and age/parameter } & \multicolumn{3}{|c|}{ Regression equations } & \multirow[t]{2}{*}{$R$} & \multirow[t]{2}{*}{ SEE } \\
\hline & $\times$ Height $(\mathbf{c m})$ & $\times$ Age (years) & Constant & & \\
\hline \multicolumn{6}{|l|}{ Male adults $\geq 20$ years } \\
\hline FVC (L) & 0.020 & -0.019 & +0.701 & 0.46 & 0.61 \\
\hline FEV1 (L) & 0.020 & -0.020 & +0.524 & 0.52 & 0.53 \\
\hline $\operatorname{PEFR}(\mathrm{L} / \mathrm{min})$ & 2.14 & -2.16 & +201.2 & 0.31 & 104.6 \\
\hline \multicolumn{6}{|l|}{ Female adults $\geq 20$ years } \\
\hline $\mathrm{FVC}(\mathrm{L})$ & 0.020 & -0.014 & +0.097 & 0.49 & 0.41 \\
\hline FEV1 (L) & 0.019 & -0.015 & +0.116 & 0.55 & 0.36 \\
\hline $\operatorname{PEFR}(\mathrm{L} / \mathrm{min})$ & 1.46 & -0.80 & +139.7 & 0.26 & 61.0 \\
\hline \multicolumn{6}{|c|}{ Male adults $>15-<20$ years } \\
\hline $\mathrm{FVC}(\mathrm{L})$ & 0.050 & +0.133 & -7.26 & 0.79 & 0.43 \\
\hline FEV1(L) & 0.046 & +0.087 & -6.08 & 0.77 & 0.41 \\
\hline $\operatorname{PEFR}(\mathrm{L} / \mathrm{min})$ & 5.05 & +14.5 & -670.0 & 0.57 & 82.6 \\
\hline \multicolumn{6}{|c|}{ Female adults $>15-<20$ years } \\
\hline FVC (L) & 0.024 & +0.130 & -3.42 & 0.45 & 0.42 \\
\hline FEV1 (L) & 0.021 & +0.110 & -2.93 & 0.48 & 0.34 \\
\hline PEFR (L/min) & 2.64 & +23.4 & -485.9 & 0.43 & 63.4 \\
\hline \multicolumn{6}{|l|}{ Male children $\leq 15$ years } \\
\hline FVC (L) & 0.026 & +0.026 & -2.06 & 0.61 & 0.4 \\
\hline FEV1 (L) & 0.025 & +0.033 & -2.16 & 0.69 & 0.32 \\
\hline PEFR (L/min) & 2.25 & +15.9 & -238.3 & 0.63 & 58.4 \\
\hline \multicolumn{6}{|l|}{ Female children $\leq 15$ years } \\
\hline FVC (L) & 0.018 & +0.064 & -1.29 & 0.57 & 0.42 \\
\hline FEV1 (L) & 0.014 & +0.067 & -1.04 & 0.6 & 0.34 \\
\hline $\operatorname{PEFR}(\mathrm{L} / \mathrm{min})$ & 1.69 & +3.93 & -25.3 & 0.45 & 47.0 \\
\hline
\end{tabular}

$R=$ multiple correlation coefficient; $S E E=$ standard error of the estimate.

$F V C=$ forced vital capacity; $F E V 7=$ forced expiratory volume in 1 second; $P E F R=$ peak expiratory flow rate

is in agreement with the results of other investigators [3.9]. The lowest mean values of FVC and FEV1 were found in the age group $71-80$ years.

There was significant negative correlation in adults between age and ventilatory function $(r=0.49)$, which is comparable with the findings in the literature. The significant positive correlation between standing height and measures of lung volume $(r=0.52)$ is in general agreement with the results of other investigators on Europeans and non-Europeans. The decline in ventilatory function with age agrees with other studies showing deterioration of pulmonary function with advancing age, even in the absence of impairment by respiratory disease, cigarette smoking or atmospheric pollution [18-22].
The observed positive correlation of weight with ventilatory function is in agreement with studies in other countries $[5,21,23]$, although other reports stated that lung function decreased at both extremes of weight $[24,25]$. These reports are supported also by our results that a drop in ventilatory volumes was observed in the highest weight category of $90-100 \mathrm{~kg}$. The correlation of weight with lung function almost disappeared when we used a population of the same age and height, so the observable correlation of weight with lung function may be due to age and height variations rather than weight itself.

The high correlation between FEV1 and FVC found in this study ( $r$ $=0.97)$ is comparable with the work of many investigators on Europeans and non-Europeans [26]. There was a significant correlation between PEFR and FEV1 $(r=0.75)$, which is comparable with the results of Johannsen and Erasmus in normal African Bantu [27], where they found $r=0.58$. The significant correlation between FVC and PEFR $(r=0.70), \mathrm{FVC}$ and FEV1/ FVC\% $(r=-0.12)$ and between PEFR and FEV1/FVC\% $(r=0.29)$ are to some extent comparable to those found by Johannsen and Erasmus [27]: $(r=0.38),(r=-0.15)$ and $(r=$ $0.36)$ respectively.

This study has calculated regression equations for predicting the normal values of ventilatory functions of Sudanese for FVC, FEV1, PEFR and FEV1/ $\mathrm{FVC} \%$. Although we have derived 


\begin{tabular}{|c|c|c|c|c|}
\hline \multirow[t]{2}{*}{ Region/parameter } & \multicolumn{3}{|c|}{ Regression equations } & \multirow[t]{2}{*}{ Predicted mean } \\
\hline & $\times$ Height $(\mathrm{cm})$ & $\times$ Age (years) & Constant & \\
\hline \multicolumn{5}{|l|}{ West Sudan } \\
\hline $\mathrm{FCV}(\mathrm{L})$ & 0.035 & -0.019 & -1.89 & 3.43 \\
\hline FEV1 (L) & 0.030 & -0.023 & -1.29 & 3.19 \\
\hline PEFR (L/min) & 2.49 & -3.37 & +183.9 & 505.8 \\
\hline \multicolumn{5}{|l|}{ East Sudan } \\
\hline $\mathrm{FCV}(\mathrm{L})$ & 0.026 & -0.018 & -0.21 & 3.71 \\
\hline FEV1 (L) & 0.029 & -0.018 & -0.99 & 3.37 \\
\hline $\operatorname{PEFR}(\mathrm{L} / \mathrm{min})$ & 3.86 & -1.81 & -89.0 & 513.2 \\
\hline \multicolumn{5}{|l|}{ Central Sudan } \\
\hline $\mathrm{FCV}(\mathrm{L})$ & 0.011 & -0.021 & +2.48 & 3.72 \\
\hline FEV1 (L) & 0.008 & -0.022 & +2.70 & 3.39 \\
\hline $\operatorname{PEFR}(\mathrm{L} / \mathrm{min})$ & 1.06 & -3.10 & +410.2 & 497.0 \\
\hline \multicolumn{5}{|l|}{ North Sudan } \\
\hline $\mathrm{FCV}(\mathrm{L})$ & 0.015 & -0.030 & +2.75 & 3.85 \\
\hline FEV1 (L) & 0.015 & -0.026 & +1.67 & 3.41 \\
\hline PEFR (L/min) & 2.93 & -0.54 & +45.5 & 528.0 \\
\hline \multicolumn{5}{|l|}{ South Sudan } \\
\hline $\mathrm{FCV}(\mathrm{L})$ & 0.019 & -0.070 & +1.50 & 3.45 \\
\hline FEV1 (L) & 0.019 & -0.370 & +0.99 & 3.15 \\
\hline $\operatorname{PEFR}(\mathrm{L} / \mathrm{min})$ & 3.95 & -6.72 & -16.77 & 485.7 \\
\hline \multicolumn{5}{|l|}{ Total } \\
\hline $\mathrm{FCV}(\mathrm{L})$ & 0.020 & -0.019 & +0.70 & 3.59 \\
\hline FEV1 (L) & 0.020 & -0.020 & +0.52 & 3.28 \\
\hline $\operatorname{PEFR}(\mathrm{L} / \mathrm{min})$ & 2.14 & -2.16 & +201.2 & 499.5 \\
\hline
\end{tabular}

aPredicted means values for adult male Sudanese ( $\geq 20$ years) of height $170 \mathrm{~cm}$ and age 30 years.

$F V C=$ forced vital capacity; $F E V 7=$ forced expiratory volume in 1 second; $P E F R=$ peak expiratory flow rate

separate equations for each region the insignificant difference between the regional Sudanese lung function values and the combined values from the whole country means that the general prediction equations are valid for all $\mathrm{Su}$ danese. It is noteworthy that regression equations using age and height as independent variables for prediction of PEFR had low correlation coefficients and large standard errors of the estimate, so the prediction equations should be used with awareness of these limitations.
Sudanese of Arab ethic origin had significantly higher FVC than those of African ancestry by comparing the direct observed means and also by comparing the predicted means. The predicted value of FVC, FEV1 and PEFR in Arab Sudanese were higher than those

Table 8 Predicted and actual lung function values for Sudanese adult males of Arab and African ethic backgrounds (at height $170 \mathrm{~cm}$ and 35 age years)

\begin{tabular}{lcccc} 
Parameter & \multicolumn{2}{c}{ Arab Sudanese $^{\mathrm{a}}$} & \multicolumn{2}{c}{ African Sudanese $^{\mathrm{b}}$} \\
& Predicted mean & Actual mean (SD) & Predicted mean & Actual mean (SD) \\
FVC (L) & 3.66 & $3.92(0.67)$ & 3.26 & $3.67(0.53)$ \\
FEV1 (L) & 3.26 & $3.48(0.63)$ & 2.96 & $3.31(0.47)$ \\
PEFR (L/min) & 519 & $517(108)$ & 419 & $486(92)$ \\
FEV1/FVC (\%) & 89 & & 91 & \\
\hline
\end{tabular}

${ }^{a}$ North, west and east Sudanese, ${ }^{b}$ South Sudanese.

$S D=$ standard deviation

$F V C=$ forced vital capacity; FEVI = forced expiratory volume in 1 second; PEFR = peak expiratory flow rate 


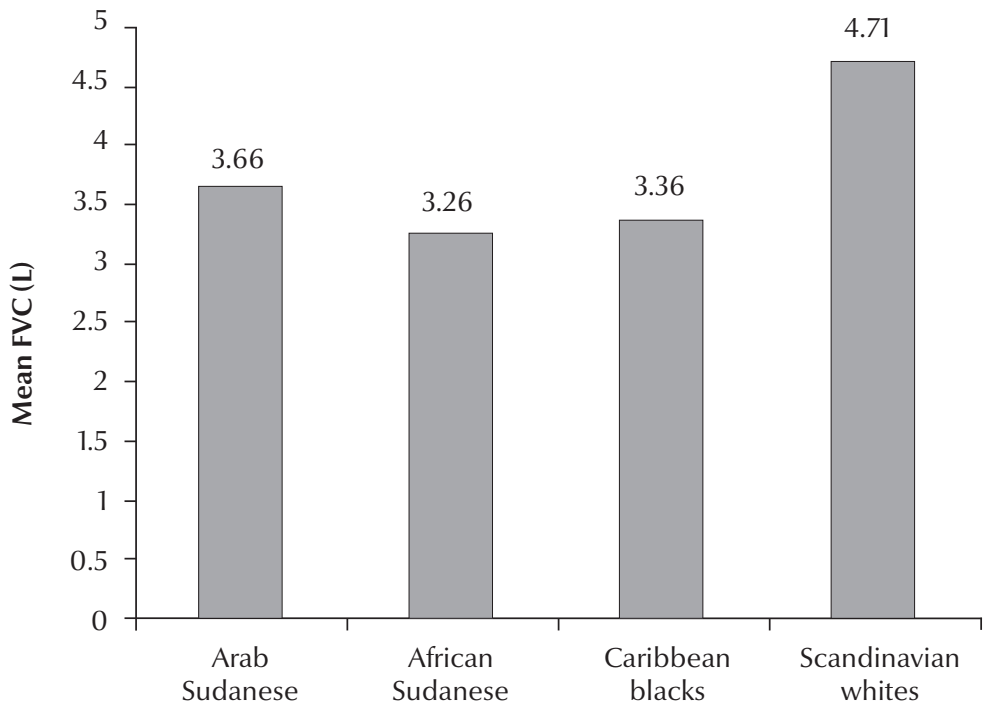

Figure 1 Forced vital capacity (FVC) of adult male Sudanese of Arab and African ethnic backgrounds: comparison with data from other ethnic groups [15,16]

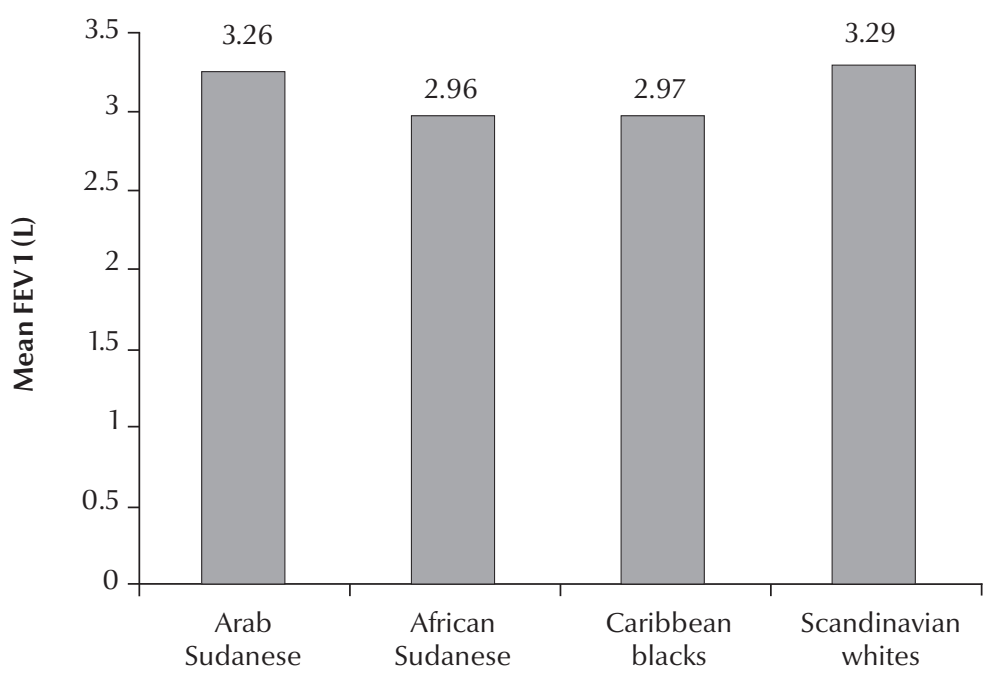

Figure 2 Forced expiratory volume in 1 second (FEV1) of adult male Sudanese of Arab and African ethnic backgrounds: comparison with data from other ethnic groups $[15,16]$ of African Sudanese. The presence of a detectable ethnic variation in lung function between the northern and southern Sudanese people, reflecting Arab and African ethnic origins, encouraged us to derive other equations for the people of the west, east and central Sudan. The predicted lung function values of the eastern and central Sudanese were in between the values for northern and southern Sudanese. The total predicted lung function values for all Sudanese did not differ from the values obtained by equations for each region, which indicates that there is no need for separate tables for each region.

The lung function values of Sudanese were lower than those of white Europeans [16] (Figures 1 and 2). The predicted $\mathrm{FVC}$ values of the present study were $83.5 \%$ of that of whites according to Needham's equation [28]. The predicted FEV1 values of the present study were $86.1 \%$ of that of whites according to Anderson's equation [29]. There were no major differences in FVC and FEV1 between values for Caribbean blacks [15] and those of African Sudanese in our study (Figures 1 and 2). However, the present study predicted higher values for FEV1/FVC\% (90.6\% overall) than other studies, although this value is closer to that reported by Khatim in northern Sudanese subjects (87.0\%) [9] and by Kaloda in Wad Medani in central Sudan (88.6\%) [11].

In conclusion, normal values established for FVC, FEV1, FEV1/FVC\% and PEFR in this study can be used as reference values in respiratory clinics in Sudan.

\section{References}

1. Hsi BP, Hsu KHK, Jerkins DE. Ventilatory function of normal children and young adults: Mexican-American whites and blacks: 111. Sitting height as predictor. Journal of Pediatrics, 1983, 102:860-865.

2. Abramowitz $\mathrm{S}$ et al. Vital capacity in the Negro. American Review of Respiratory Disease, 1965, 92:287.

3. Johannsen ZM, Erasmus CD. Clinical spirometry in normal Bantu. American Review of Respiratory Disease, 1968, 97:585-597.
4. Miller GJ et al. Ethnic variation in forced expiratory volume and forced vital capacity of African and Indian adults in Guyana. American Review of Respiratory Disease, 1970, 102:979-981.

5. Crapo RO et al. Normal spirometric values in healthy Hispanic Americans. Chest, 1990, 98:1435-1439.

6. Morris JF, Koski A,. Johnson LC. Spirometric standards for healthy non-smoking adults. American Review of Respiratory Disease, 1971, 103:57-67. 
7. Crouse U, Laine-Alava MT. Effect of age, body mass index, and gender on nasal airflow rates and pressures. Laryngoscope, 1999, 109:1503-1508.

8. Morton AR et al. Spirometric values for normal Perth children aged six to twelve years. Australian and New Zealand Journal of Medicine, 1976, 6:51-57.

9. Khatim MY. Spirometric lung function tests of normal men of African ethnic origin. American Review of Respiratory Disease, 1977, 116:209-213.

10. Khatim MY. Ventilatory function tests: a comparative study among Sudanese and Egyptian students. Sudan Medical Journal, 1983, 2:5-54.

11. Kaloda Y. Reference spirometric measurements in Sudanese in Wad Medani [MSc dissertation]. Department of Physiology, University of Gezira, Wad Medani, Sudan, 1998.

12. Enarson DA et al. Research methods for the promotion of lung health: a guide to protocol development for low income countries. Paris, International Union Against Tuberculosis and Lung Diseases, 2001.

13. Donoghue WC. How to measure your \% body fat: an instruction manual for the Slim Guide skin fold caliper. Ann Arbor, Michigan, Creative Health Products, 1987.

14. Dirksen A et al. Long term performance of a hand held spirometer. Thorax, 1996, 51:973-976.

15. Miller GJ et al. Lung function and exercise performance of healthy Caribbean men and women of African ethnic origin. Quarterly Journal of Experimental Physiology, 1972, 57:325.

16. Berglund E et al. Spirometric studies in normal subjects: Forced expirograms in subjects between 7 and 70 years of age. Acta Medica Scandinavica, 1963, 173:185.

17. White NW et al. Review and analysis of variation between spirometric values reported in 29 studies of healthy African adults. American Journal of Respiratory and Critical Care Medicine, 1994, 150:348-355.
18. Knudson RJ et al. Changes in normal maximal expiratory flow-volume curve with growth and aging. American Review of Respiratory Disease, 1983, 127:725-734.

19. Morris JF, Koski A, Johnson LC. Spirometric standards for healthy non-smoking adults. American Review of Respiratory Disease, 1971, 103:57-67.

20. Gilson JC. Changes in lung function with age. In: Proceedings of Pneumoconiosis Conference, Johannesburg, South Africa, 1959

21. Kory RC et al. The Veterans Administration-Army Cooperative Study of Pumonary Function: Clinical spirometry in normal men. American Journal of Medicine, 1961, 30:234.

22. Grimbly G, Soderholm B. Spirometric studies in normal subjects. III Static lung volumes and maximum voluntary ventilation in adults with a note on physical fitness. Acta Medica Scandinavica, 1963, 173:199-206.

23. Ray CS et al. Effect of obesity on respiratory function. American Review of Respiratory Disease, 1983, 128:501-506.

24. Schoenberg JB, Beck GJ, Bouhuys A. Growth and decay of pulmonary function in healthy blacks and whites. Respiration Physiology, 1978, 33:367-393.

25. Dockery DW, Ware JH, Ferris BG. Distribution of forced expiratory volume in one second and forced vital capacity in healthy white adults never-smokers in six U.S cities. American Review of Respiratory Disease, 1985, 131:511-520.

26. Ferris BG, Anderson DO, Zickmantel R. Prediction values for screening tests of pulmonary function. American Review of Respiratory Disease, 1965, 91:252.

27. Johannsen ZM, Erasmus CD. Clinical spirometry in normal Bantu. American Review of Respiratory Disease, 1968, 97:585-597.

28. Needham CD, Rogan MC, McDonald I. Normal standards for lung volumes, intrapulmonary gas mixing and maximum breathing capacity. Thorax, 1954, 9:313.

29. Anderson DO. Smoking and respiratory disease. American Journal of Public Health, 1964, 54:1856. 